\title{
Patients with Postpartum Depression in Gynaecological Practices in Germany - Results of a Representative Survey of Local Gynaecologists about Diagnosis and Management
}

\author{
Patientinnen mit postpartaler Depression in Frauenarztpraxen in Deutschland - \\ Ergebnisse einer Repräsentativerhebung niedergelassener Gynäkologen zur Diagnostik und Versorgung
}

Authors

Affiliations
S. Pawils ${ }^{1 *}$, F. Metzner ${ }^{1 *}$, C. Wendt ${ }^{1}$, S. Raus ${ }^{1}$, M. Shedden-Mora ${ }^{2}$, O. Wlodarczyk ${ }^{1}$, M. Härter ${ }^{1}$

${ }^{1}$ Universitätsklinikum Hamburg-Eppendorf, Institut für Medizinische Psychologie, Hamburg

${ }^{2}$ Universitätsklinikum Hamburg-Eppendorf, Poliklinik für Psychosomatische Medizin und Psychotherapie, Hamburg
Deutsche Version unter: http://dx.doi.org/ $10.1055 / \mathrm{s}-0042-103326$

\section{Abstract \\ $\nabla$}

Theoretical Background and Current Issues: For the sake of pre-emptive child protection it is necessary to recognise signs of postpartum depression (PPD) in pregnant women and young mothers as early as possible and to initiate adequate assistance. Because of their high acceptance, especially in the phases of pregnancy and birth, the local gynaecologists offer ideal prerequisites for access to the parents. This study evaluates the current status of diagnosis and management of PPD in gynaecological practices.

Material and Methods: In a representative German nation-wide questionnaire survey taking the regional distribution into account $\mathrm{n}=3000$ local gynaecologists were selected at random and contacted by post. The questionnaire addressed their approaches to the diagnosis and management of PPD as well as the encountered barriers. Results: Among the $\mathrm{n}=1034$ participating gynaecologists (response rate: $35 \%$ ) half of them dealt actively with PPD; $16 \%$ used a questionnaire for this purpose. Consultation by the gynaecologist (84\%) or referral to therapists or hospitals (86\%) were among the most common interventions in the management of PPD. A need for improvement in the management of women with PPD was recognised equally often. As barriers the gynaecologists mentioned above all the lack of time, the low reimbursements for consultations and the lack of effective treatment options. Predictors for an active anamnesis were found to be female gender of the gynaecologist, possession of an additional psychosomatic qualification and practice located in an urban catchment area or state of the former West Germany.

Conclusion: The results clearly demonstrate a high acceptance for the management of PPD by gynaecologists as well as the need for further action to improve the care of patients with PPD in gynaecological practices.

\section{Zusammenfassung \\ $\nabla$}

Theoretischer Hintergrund und Fragestellungen: Im Sinne des präventiven Kinderschutzes gilt es, Anzeichen für die postpartale Depression (PPD) bei Schwangeren und Müttern frühzeitig $\mathrm{zu}$ erkennen und adäquate Hilfe anzubahnen. Niedergelassene Gynäkologen bieten aufgrund ihrer hohen Akzeptanz insbesondere in der Phase von Schwangerschaft und Geburt ideale Bedingungen für den Zugang zu Eltern. Diese Studie erfasst den aktuellen Stand zu Diagnostik und Versorgung von PPD in gynäkologischen Praxen.

Material und Methodik: In einer deutschlandweiten, hinsichtlich der regionalen Verteilung repräsentativen Fragebogenuntersuchung wurden $\mathrm{n}=3000$ niedergelassene Gynäkologen zufällig ausgewählt und angeschrieben. Der Fragebogen erfasste die Herangehensweise zur Diagnostik und Versorgung der PPD sowie wahrgenommene Barrieren.

Ergebnisse: Von den teilnehmenden $n=1034$ Frauenärzten (Rücklaufquote: $35 \%$ ) erfasste die Hälfte eine PPD aktiv; 16\% nutzten dafür einen Fragebogen. $\mathrm{Zu}$ den häufigsten Interventionen beim Vorliegen einer PPD zählte die Beratung durch den Frauenarzt (84\%) oder die Überweisung an Therapeuten oder Kliniken (86\%). Ebenso häufig wurde Verbesserungsbedarf bei der Versorgung von Frauen mit PPD gesehen. Barrieren sahen die Frauenärzte vor allem in der mangelnden Zeit, der geringen Vergütung der Beratung und fehlenden effektiven Behandlungsmöglichkeiten. Als Prädiktoren für eine aktive Anamnese zeigten sich weibliches Geschlecht des Arztes, Vorliegen einer psychosomatischen Zusatzqualifizierung und Praxis in einem städtischen Einzugsgebiet oder den alten Bundesländern.

\footnotetext{
* Equal contributions as first author.
} 
Schlussfolgerung: Die Ergebnisse verdeutlichen die hohe Akzeptanz für die Versorgung der PPD durch Gynäkologen sowie weiteren Handlungsbedarf, um die Versorgung von Patientinnen mit einer PPD in gynäkologischen Praxen zu verbessern.

\section{Introduction}

$\nabla$

With a prevalence of 10 to $15 \%$ [1-3] postpartum depression (PPD) is one of the most common psychological disorders of women during pregnancy and after birth. Halbreich and Karkun [2] evaluated 143 studies on the frequency of PPD world-wide and determined the prevalence to be between $0 \%$ and $60 \%$ depending on the tool, chosen cut-off and time period after birth investigated. In Germany von Ballestrem et al. [4] found a prevalence for PPD of 3.6\% in a random sample of 722 mothers; however, there are only very few empirical studies on the frequency of PPD in Germany. Postpartum (or postnatal) depression or PPD, coded in ICD-10 as a mild mental and behavioural disorder in childbed, not classified elsewhere (F53.0), is a maternal depressive disorder characterised by fear of failure, emotional ambivalence and insensitivity that often begins in the first to sixth week after birth of the baby but can also occur already during pregnancy [5]. PPD is often identified as a predictor for attachment disorders [6], infanticide [7], developmental disabilities [8] and a later depressive disease of the child [9]. Mental problems of the parents such as affective disorders also belong to the most important risk factors for endangerment of the child's welfare [10]. Against the background of an increased risk for impairment of the child's development, the treatment of PPD is of particular relevance.

With regard to PPD in Germany there is a clear management deficit due to the lack of psychotherapeutic options for mothers with new-born babies. PPD often leads to a feeling of shame among the afflicted mothers, they fear stigmatisation, separation from the baby or they are not consciously aware of their disorder or the available possibilities for help [11]. According to the study of Le Strat et al. [12] women with postpartum psychological disorders less frequently take advantage of available help than do mentally ill women who are not in the postpartum period. In addition, the need for therapeutic options to treat PPD in motherchild facilities that, besides the treatment of PPD, also address the relationship to the baby without requiring separation from the child is only covered in Germany to about $21 \%$ [13]. Since as yet no highly promising results have been achieved for the primary prevention of PPD [14], the early recognition and treatment of PPD is especially important [15]. Available as screening tools for PPD are the Bromley Postnatal Depression Scale [16], the Postpartum Depression Checklist (PDC; [17]), the Postpartum Depression Screening Scale (PDSS; [18]) as well as the Edinburgh Postnatal Depression Scale (EPDS; $[19,20]$ ), a self-assessment questionnaire (10 items) which is also widely distributed in Germany. Since the afflicted women are often not able on their own to describe their psychological problems, a more active handling of psychological disorders in the period of pregnancy and after birth is particularly important [15]. On account of their sensitivity and specificity as confirmed in a meta-analysis [21], the EPDS and the Patient Health Questionnaire (PHQ; [22]) are recommended as screening tools for PPD after birth in the S3 guidelines for unipolar depression (consultation version) [23]. During the childbed period in which the PPD symptoms frequently occur for the first time, together the midwife and the gynaecologist are the primary contact persons for the young mother and play a significant role in the earliest possible recognition of PPD and, if necessary, referral of the afflicted patient during pregnancy and in the first six to twelve months after birth to psychotherapeutic services, for example, as part of the post-natal care [24]. The recognition and treatment of pregnancy-related psychological diseases such as PPD is as yet in Germany not a regular component of general medical education or specialist training in the field of gynaecology and obstetrics.

In this German nation-wide survey of local gynaecologists the following questions were posed: What diagnostics do gynaecologists in Germany carry out for pregnant women and mothers with a suspicion of PPD? What management possibilities do gynaecologists see for patients with PPD? From the gynaecologist's point of view what barriers are there to the diagnosis and management of mothers with PPD? What factors from the gynaecologist's point of view influence the active diagnosis and consultations of patients suffering from PPD?

\section{Materials and Methods \\ $\nabla$}

\section{Execution}

In the framework of a nation-wide questionnaire survey, $\mathrm{n}=3000$ practicing gynaecologists were asked about their handling of patients with a suspicion of PPD. The sample was chosen at random from a basic population of $n=9823$ addresses of registered gynaecologists in Germany recorded in the database of the address service provider "MediAdressen Select" in January 2013. In a first step every third practice ordered according to post code was selected and from this sample in a second step every 12th practice as well as those practices that had already participated in a preliminary study were excluded ( $\bullet$ Fig. 1 ). According to the physician statistics of the German Medical Association there were $\mathrm{n}=9784$ specialists for gynaecology and obstetrics registered in Germany in 2012 [25]. The difference between the number of registered physicians in the employed address list and in the physician statistics of the German Medical Association $(n=39)$ can be explained by different reporting dates and different means of data acquisition of the two sources. In contrast to the German Medical Association, the address provider service uses only public sources for address research in accord with the Federal Data Protection Law so that, for example, the closing of medical practices may have been recorded only after a delay of several months.

A preliminary study was carried out in autumn 2012 in n = 15 gynaecology practices in Hamburg and served to test the questionnaire with respect to its comprehensibility, relevance and practicability as well as to investigate appropriate incentives and formulation of the accompanying letter.

In spring 2013 two survey waves (invitation, reminder) at an interval of one month were undertaken in which the $n=3000$ selected gynaecologists were contacted by post. Reasons for nonparticipation such as, for example, closure of the practice were acquired by means of a pre-stamped postcard sent with the second letter that could be returned gratis by the non-participants. 


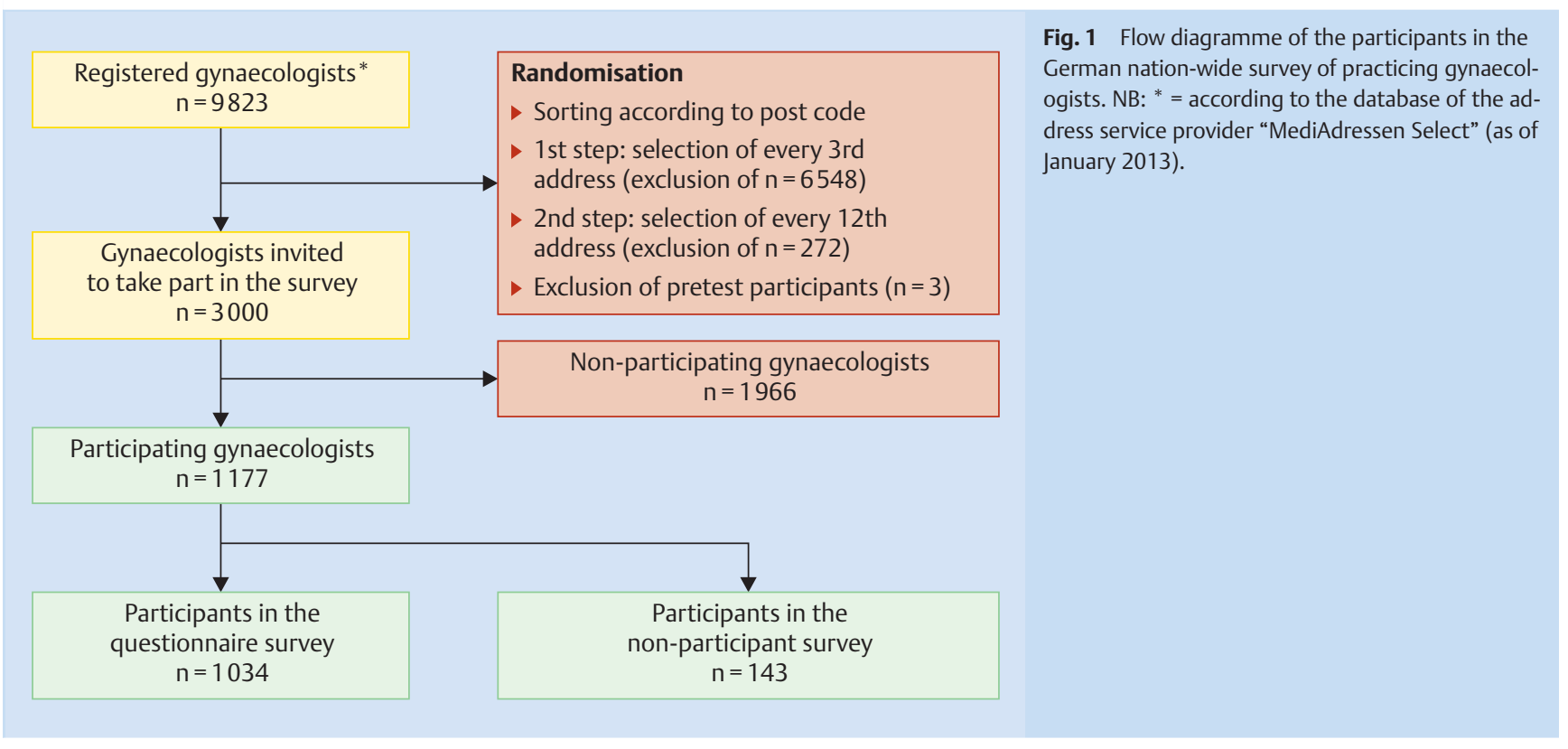

In addition, demographic data about the non-participant could be extracted from the practice stamp on the postcard, e.g., type of practice and location.

\section{Instruments}

For this survey of practicing gynaecologists a questionnaire encompassing 28 items was used, it was developed on the basis of the findings from surveys of comparable samples (e.g., Berner et al. [26]). The questionnaire contained details of a) practice and person, b) diagnostics and handling of patients with a suspicion of PPD as well as c) system- and patient-related barriers to management in both open and closed answer formats. Multiple answers were possible for many items.

\section{Sample}

Of the 3000 contacted gynaecologists $n=1034$ took part in the questionnaire survey. The response rate thus amounted to $35 \%$. The proportion of male gynaecologists of $36 \%$ was lower than the average proportion of practicing gynaecologists in the year 2012 (41\% male; [25]). On average the participating gynaecologists were 52 years old $(S D=7.5)$ and in the age range of 35 to 73 years. The duration of professional activity was on average 24 years ( $\mathrm{SD}=8.4$, range: $1-55$ years. More than half of the participants ( $58 \% ; n=621$ ) reported that they had gained additional qualifications, $74 \%$ with psychosomatic or therapeutic further training $(n=448), 44 \%$ with additional medical qualifications $(\mathrm{n}=264)$ and $15 \%$ with alternative methods such as acupuncture or natural therapies $(n=90)$. The majority were active in oneperson practices (61\%) and in the "old" federal states including Berlin (85\%). For 38\% $(n=385)$ of the participating gynaecologists their catchment areas were urban, for $25 \%(n=251)$ rural and for $37 \%(n=367)$ both urban and rural. The average number of pregnant women treated per year was $150 ; 75 \%$ of the participating gynaecologists managed up to 300 pregnant women per year in their own practices.

Demographic data for the participating gynaecologists were compared with representative data for the registered gynaecologists in Germany [24] ( Table 1). The regional distribution of the participants in the federal states or, respectively, in the "new" and "old" federal states is comparable with that of the entire cohort of practicing gynaecologists in Germany. Male and gynaecologists aged more than 50 years are underrepresented in the sample.

\section{Non-participants}

Only $7 \%$ ( $n=143$ of $n=1966)$ of the non-participants returned the postcard giving reasons for not taking part in the analysis. Most of these non-participants were active in single-person practices (75\%) and located in the old federal states (84\%). About $47 \%$ of the non-participants were male. The non-participants differed significantly with regard to gender and practice from the participants in this nation-wide survey; with regard to location in the old or new federal states there was no significant difference between the participants and the non-participants.

Reasons given for not participating were for $44 \%(n=62)$ lack of time; $23 \%(n=33)$ reported that they had other specialist fields of activity or, respectively, focused on other target groups. Seventeen percent $(n=24)$ were not interested in the survey, whereas $15 \%(n=21)$ had previously had bad experiences with surveys. About $11 \%(n=16)$ of the non-participants stated that they had closed their practices, e.g., due to retirement or change of location. Thus, it can be assumed that these physicians were still recorded in the address database of the address service provider due to a delayed data actualisation. This may in part explain the difference in physician statistics. Miscellaneous reasons for nonparticipation were given by $7 \%(n=10)$.

\section{Representativeness of the sample}

For an assessment of the representativeness of the present crosssectional survey, three factors that could limit the representativeness of the survey were examined:

1. The target population is not sufficiently clearly defined,

2. Selection of the sample was not random (e.g., for reasons of practicability) and

3. there is a non-response bias, i.e., differences between participants and non-participants.

Under consideration of the preformed target group definition, the procedure chosen to select the sample and a comparison of the observed characteristics of the sample with the characteris- 
Table 1 Sociodemographic characteristics of the sample of registered gynaecologists in the study group $(n=1034)$ compared with the entire cohort of registered gynaecologists in Germany according to physician statistics of the German Medical Association (GBE, 2015).

\begin{tabular}{|c|c|c|c|}
\hline & $\begin{array}{l}\text { Sample of } \\
\text { the nation- } \\
\text { wide survey } \\
\% \text { (n) }\end{array}$ & $\begin{array}{l}\text { Registered } \\
\text { gynaecologists } \\
\text { in Germany } \\
\% \text { (n) }\end{array}$ & $\mathbf{p}^{\mathbf{b}}$ \\
\hline & $(n=1034)$ & $(n=9784)$ & \\
\hline Gender & & & ** \\
\hline > male & $366(36 \%)$ & 4054 (41\%) & \\
\hline - female & 656 (64\%) & 5730 (59\%) & \\
\hline Age (years) & & & $* * *$ \\
\hline - under 40 years & $28(4 \%)$ & $288(3 \%)$ & \\
\hline - 40 to under 50 years & $256(34 \%)$ & $2918(30 \%)$ & \\
\hline - 50 to under 60 years & 332 (44\%) & $4147(43 \%)$ & \\
\hline - 60 to under 66 years & $112(15 \%)$ & $1675(17 \%)$ & \\
\hline more than 66 years & $22(2 \%)$ & $756(8 \%)$ & \\
\hline Federal states & & & n.s. \\
\hline - Baden-Württemberg & $122(12 \%)$ & $1234(13 \%)$ & \\
\hline - Bavaria & $143(14 \%)$ & $1529(16 \%)$ & \\
\hline - Berlin & $49(5 \%)$ & $498(5 \%)$ & \\
\hline - Brandenburg & $21(2 \%)$ & $266(3 \%)$ & \\
\hline Bremen & $14(1 \%)$ & $110(1 \%)$ & \\
\hline - Hamburg & $35(4 \%)$ & $278(3 \%)$ & \\
\hline - Hesse & $66(7 \%)$ & $683(7 \%)$ & \\
\hline $\begin{array}{l}\text { Mecklenburg- } \\
\text { Western Pomerania }\end{array}$ & $20(2 \%)$ & $185(2 \%)$ & \\
\hline - Lower Saxony & $105(10 \%)$ & $917(9 \%)$ & \\
\hline - North Rhine Westphalia & $220(22 \%)$ & $2269(23 \%)$ & \\
\hline - Rhineland-Palatinate & $57(6 \%)$ & $429(4 \%)$ & \\
\hline - Saarland & $12(1 \%)$ & $120(1 \%)$ & \\
\hline - Saxony & $63(6 \%)$ & $467(5 \%)$ & \\
\hline - Saxony-Anhalt & $34(3 \%)$ & $237(2 \%)$ & \\
\hline - Schleswig-Holstein & $35(4 \%)$ & $334(3 \%)$ & \\
\hline Thuringia & $16(2 \%)$ & $228(2 \%)$ & \\
\hline New vs. old Federal states & & & n.s. \\
\hline - New Federal states & $154(15 \%)$ & $1383(14 \%)$ & \\
\hline $\begin{array}{l}\text { Old Federal states } \\
\text { (incl. Berlin) }\end{array}$ & $858(85 \%)$ & 8401 (86\%) & \\
\hline
\end{tabular}

a Data from the physicians statistics of the German Medical Association for the year 2012 (2015); ${ }^{b} \mathrm{X}^{2}$ test according to Pearson; ${ }^{*} \mathrm{p}<0.05,{ }^{* *} \mathrm{p}<0.01,{ }^{* * *} \mathrm{p}<0.001$

tics of the target population or, respectively, the non-participants it can be assumed that the sample is very probably representative with regard to the regional distribution between the new and the old federal states for the registered gynaecologists in Germany at the time of the survey in the Spring of 2013.

\section{Statistical evaluation}

The results of the survey were analysed descriptively. In order to determine the outcome-influencing factors in the performance of an active diagnosis and consultation in cases of PPD, binary logistic regressions were undertaken.

\section{Results}

\section{Diagnostics of PPD}

Half of the surveyed gynaecologists estimated the incidence of PPD among patients in their own practices to be $3 \%, 75 \%$ of the participants estimated the incidence of PPD to be up to $5 \%$. The
Table 2 Procedures used by the participating gynaecologists in the diagnostics for PPD ( $n=1034)$.

\begin{tabular}{|c|c|c|}
\hline Diagnostic methods* & $\mathbf{n}$ & $\%$ \\
\hline \multicolumn{3}{|l|}{ Detection during consultations } \\
\hline Overall frequency of consultations & 1003 & $99 \%$ \\
\hline specific questioning & 510 & $50 \%$ \\
\hline coincidental procedure & 523 & $52 \%$ \\
\hline \multicolumn{3}{|l|}{ Detection using a questionnaire } \\
\hline Overall frequency of questionnaire use & 165 & $16 \%$ \\
\hline of which: $\quad$ routine use & 62 & $6 \%$ \\
\hline use as needed & 100 & $10 \%$ \\
\hline \multicolumn{3}{|l|}{ Detection through tips for third persons } \\
\hline Overall frequency & 733 & $72 \%$ \\
\hline \multicolumn{3}{|l|}{ Number of diagnostic methods } \\
\hline $\begin{array}{l}\text { None of the } 3 \text { methods (consultation, } \\
\text { questionnaire, third person) }\end{array}$ & 7 & $1 \%$ \\
\hline 1 method & 234 & $23 \%$ \\
\hline 2 methods & 651 & $64 \%$ \\
\hline 3 methods & 119 & $12 \%$ \\
\hline \multicolumn{3}{|l|}{ Active anamnesis } \\
\hline $\begin{array}{l}\text { Targeted questioning or routine use } \\
\text { of questionnaire }\end{array}$ & 539 & $53 \%$ \\
\hline
\end{tabular}

gynaecologists gained the suspicion of PPD mainly in consultations with the patients (99\%) or through informative tips from third persons, e.g., midwifes, medical assistants or relatives (72\%), whereby multiple answers were possible (O Table 2 ). About $50 \%$ of the surveyed physicians specifically sought suggestions for PPD during the consultations. A questionnaire as screening tool for PPD was employed by $16 \%$ of the gynaecologists. A questionnaire for PPD was routinely used by 62 of the 1034 participants (6\%), whereas $10 \%$ used a questionnaire when needed. More than half of the participating gynaecologists reported the use of more than one method to detect evidence for PPD.

\section{Interventions and mediation for mental burdens}

One of the most frequent interventions for patients with PPD is the consultation with a gynaecologist, which was reported as an intervention by $84 \%$ of the participating physicians. Patients with PPD are referred to a therapist or a hospital by the majority of the gynaecologists (86\%). About $1 \%$ of the registered gynaecologists did not mention any interventions for the management of patients with PPD.

Of the $\mathrm{n}=1034$ surveyed registered gynaecologists, $96 \%$ felt themselves to be responsible for the recognition of PPD in their patients ("yes, of course" or "generally yes").

\section{Barriers for diagnostics and management}

Among the most frequent problems from the registered gynaecologists' point of view in the care of patients with PPD are the limited time available for consultation (74\%), the low reimbursement for consultations (53\%), the lack of effective treatment and management options (50\%), the lack of recognition of the diagnosis by the partner ( $48 \%$ ) and the rejection or non-utilisation of referrals by the patients (45\%). Further barriers mentioned frequently are the lack of psychotherapy places, long waits, communication problems and anxiety from stigmatisation and shame. Whereas $96 \%$ of the gynaecologists saw at least one system-related barrier, $79 \%$ of the participants also saw at least one patient-related barrier. 
Table 3 Logistic regression of active anamnesis for PPD by gynaecologists.

\begin{tabular}{|c|c|c|c|c|}
\hline $\begin{array}{l}\text { AV: active anamne- } \\
\text { sis for PPD }(n=885)\end{array}$ & $\begin{array}{l}\text { Model } \\
\text { accuracy }\end{array}$ & B & $\begin{array}{l}\text { Signifi- } \\
\text { cance }\end{array}$ & $\begin{array}{l}\text { Odds } \\
\text { ratio }\end{array}$ \\
\hline \multicolumn{5}{|l|}{ Complete model } \\
\hline$x^{2}$ & $\begin{array}{l}46.118 \\
* * *\end{array}$ & & & \\
\hline R² (Nagelkerke's) & 0.068 & & & \\
\hline Correct prediction & $59 \%$ & & & \\
\hline \multicolumn{5}{|l|}{ Predictors } \\
\hline Federal state (new) & & -0.563 & $0.004^{* *}$ & 0.57 \\
\hline $\begin{array}{l}\text { Catchment area } \\
\text { (urban) }\end{array}$ & & & $0.018^{*}$ & \\
\hline r rural & & -0.481 & $0.007^{* *}$ & 0.62 \\
\hline both & & -0.315 & 0.051 & 0.73 \\
\hline Gender (female) & & 0.373 & $0.017^{*}$ & 1.45 \\
\hline $\begin{array}{l}\text { Length of profes- } \\
\text { sional experience }\end{array}$ & & -0.003 & 0.760 & 1.00 \\
\hline $\begin{array}{l}\text { Additional qualifica- } \\
\text { tions (none) }\end{array}$ & & & $0.008^{* *}$ & \\
\hline $\begin{array}{l}\text { psychosomatic/ } \\
\text { therapeutic }\end{array}$ & & 0.604 & $0.001 * *$ & 1.83 \\
\hline $\begin{array}{l}\text { alternative healing } \\
\text { methods }\end{array}$ & & 0.021 & 0.933 & 1.16 \\
\hline purely medical & & 0.149 & 0.396 & 0.56 \\
\hline $\begin{array}{l}\text { Number of system- } \\
\text { related barrier }\end{array}$ & & 0.131 & 0.056 & 1.14 \\
\hline $\begin{array}{l}\text { Number of patient- } \\
\text { related barriers }\end{array}$ & & 0.137 & 0.118 & 1.15 \\
\hline
\end{tabular}

${ }^{*} \mathrm{p}<0.05,{ }^{* *} \mathrm{p}<0.01$. Active anamnesis: targeted questioning or routine use of questionnaire

\section{Factors influencing an active anamnesis} and consultation for PPD

An active PPD anamnesis, i.e., the specific questioning or routine control by means of a questionnaire was carried out by $53 \%$ $(\mathrm{n}=539)$ and consultations in the presence of PPD were performed by $82 \%(n=852)$ of the gynaecologists. The results of the binary logistic regressions for active anamnesis and consultation are presented in $\bullet$ Tables 3 and $\mathbf{4}$.

It can be seen that an active diagnosis for PPD is more often performed when the physician is female, possesses an additional psychosomatic qualification, and has a practice in an urban catchment area or in the old federal states.

A consultation for an existing PPD was associated with the physician's possession of an additional psychosomatic or therapeutic qualification and a higher subjective perception of system-related barriers to the management of patients with PPD from the physician's point of view.

\section{Discussion}

Since PPD is a maternal psychological disease that can seriously impair the child's development, the gynaecologists are an important instance in the period after birth, in the sense of pre-emptive child protection, to recognise the presence of PPD and to enable access to existing support facilities. In the S3 guidelines for unipolar depression [23], this observation has recently been taken into consideration by the extension and differentiation of the recommendations for the recognition and treatment of PPD thus placing PPD more strongly in the field of view of physicians and
Table 4 Logistic regression of consultations in PPD by gynaecologists.

\begin{tabular}{|c|c|c|c|c|}
\hline $\begin{array}{l}\text { AV: Consultation } \\
\text { for PPD ( } n=885 \text { ) }\end{array}$ & $\begin{array}{l}\text { Model } \\
\text { accuracy }\end{array}$ & B & $\begin{array}{l}\text { Signifi- } \\
\text { cance }\end{array}$ & $\begin{array}{l}\text { Odds } \\
\text { ratio }\end{array}$ \\
\hline \multicolumn{5}{|l|}{ Complete model } \\
\hline$x^{2}$ & $\begin{array}{l}51.297 \\
* * *\end{array}$ & & & \\
\hline R² (Nagelkerke’s) & 0.098 & & & \\
\hline Correct prediction & $85 \%$ & & & \\
\hline \multicolumn{5}{|l|}{ Predictors } \\
\hline $\begin{array}{l}\text { Active anamnesis } \\
\text { for PPD (yes) }\end{array}$ & & 0.608 & 0.190 & 1.84 \\
\hline Federal state (new) & & -0.150 & 0.559 & 0.86 \\
\hline $\begin{array}{l}\text { Catchment area } \\
\text { (urban) }\end{array}$ & & & 0.181 & \\
\hline rural & & 0.128 & 0.599 & 1.14 \\
\hline both & & 0.423 & 0.067 & 1.53 \\
\hline Gender (female) & & -0.188 & 0.393 & 0.83 \\
\hline $\begin{array}{l}\text { Length of profes- } \\
\text { sional experience }\end{array}$ & & -0.013 & 0.277 & 0.99 \\
\hline $\begin{array}{l}\text { Additional qualifica- } \\
\text { tions (none) }\end{array}$ & & & 0.097 & \\
\hline $\begin{array}{l}\text { psychosomatic| } \\
\text { therapeutic }\end{array}$ & & 0.647 & $0.022^{*}$ & 1.91 \\
\hline $\begin{array}{l}\text { - alternative healing } \\
\text { methods }\end{array}$ & & -0.142 & 0.667 & 0.87 \\
\hline purely medical & & 0.191 & 0.427 & 1.21 \\
\hline $\begin{array}{l}\text { Number of system- } \\
\text { related barriers }\end{array}$ & & 0.43 & $<0.001^{* * *}$ & 1.54 \\
\hline $\begin{array}{l}\text { Number of patient- } \\
\text { related barriers }\end{array}$ & & 0.072 & 0.572 & 1.08 \\
\hline
\end{tabular}

${ }^{*} \mathrm{p}<0.05,{ }^{* *} \mathrm{p}<0.01,{ }^{* * *} \mathrm{p}<0.001$

psychologists. The present survey was intended to illustrate the health-care situation for mothers with PPD in Germany from the point of view of registered gynaecologists. It was able to show that gynaecologists have a good access to pregnant women and young mothers and include, in addition to the somatic treatment options, the management of psychological irregularities of their patients also in view of the associated risks for the child's development. The response rate of $35 \%$ can be considered as high in the light of the response rates in comparable surveys, this can be evaluated as a sign for the current relevance of the investigated topic.

In this nation-wide and, with respect to regional distribution, representative survey the majority of the responding gynaecologists stated that the recognition of PPD belonged in their area of responsibility (97\%) although their medical education and specialist training had not prepared them for it. Fifty percent of the responding gynaecologists estimated the incidence of PPD among their own patients on the basis of their preponderantly subjective opinions in the absence of a standardised assessment method to be up to $3 \%, 75 \%$ estimated the incidence to be up to $5 \%$. This result can be taken as an indication of the great sensitivity and expertise of gynaecologists for PPD. It can be assumed that standardised PPD diagnostics in gynaecological practices would enable a more reliable detection of patients with psychological disorders.

For an adequate management of PPD a cornerstone could be a screening (e.g., by means of EPDS or PHQ) by gynaecologists and, in the case of a positive result, a consultation and, whenever necessary, referral would be recommended [23]. It was found, however, that only half of the surveyed gynaecologists actively 
looked for PPD. Merely 16\% used a questionnaire for this purpose although there are empirically supported recommendations for the use of screening tools such as the EPDS in the management of PPD [23]. While an active diagnostic procedure was used only by a minority of the gynaecologists, in cases of recognition of PPD the majority of the gynaecologists do, in accord with the guidelines, undertake a consultation or make a referral to other facilities.

Even when the clarified variance is rather small due to the predictors employed in the model, it can be deduced from this survey that PPD is more frequently addressed actively when the gynaecologist is female, has a practice in the old federal states, in an urban catchment area and possesses an additional qualification. Besides the possession of an additional qualification, a consultation is associated with the number of system-related barriers. The lower amount of active diagnostics in the new federal states could be due to the lower density of physicians there [27], which leads to a larger number of patients to be cared for and thus less time available per patient [28]. Also in rural regions there is often a shortage of physicians [27]. That female gynaecologists are more active in the diagnosis of PPD is in accord with the results from studies with general practitioners and paediatricians in which female physicians more frequently employ screenings to detect PPD and are more liable to address psychological topics $[29,30]$. An additional qualification, e.g., in psychosomatic or therapeutic fields, can lead to a stronger sensibilisation for topic-related diseases and to increased competence in professional consultations and counselling [31].

These results provide suggestions as to where improvement is necessary from the gynaecologists' point of view in order to optimise the management of patients with PPD. Above all, structural barriers such as the lack of time for consultations, the low reimbursement for consultations and the lack of effective treatment and care options were mentioned.

This study reflects the subjective perceptions of the care situation from the gynaecologist's point of view. Content, quality and efficacy of consultations and referrals were not addressed within the framework of this survey. Similarly, aspects that could improve the predictive strength of the model for active diagnostics and counselling in suspected cases of PPD were not considered since they have already proved to be relevant for the prediction for screening and treatment results in PPD (e.g., subjective importance of screening and treatment, trust in one's own diagnostic and therapeutic abilities) [32].

The non-participant analysis showed that there were significantly more men and more gynaecologists in one-person practices in the group of non-participants than in the participant group. In addition to the usual selection effects for participation in voluntary surveys, this could be due to interest and attitudes as well as possible answering tendencies in the direction of social desirability that led to selection effects among the investigated population with regard to attitudes and the mentioned procedures.

\section{Practical Conclusions}

$\nabla$

The diagnosis and care of patients with PPD in the framework of gynaecological management is already accepted as one of their tasks by many registered gynaecologists in Germany. In the light of the empirically confirmed relationship between maternal PPD and impaired development of the child through to endangerment of the child's welfare, improvements are necessary at the following levels:

- disorder-specific qualification of gynaecologists within the framework of medical studies and advanced specialist training,

- use of a systemic diagnostic work-up for detecting PPD to increase the sensitivity for PPD symptoms,

- consideration of risk factors for PPD during gestation and after birth, as well as

- establishment of suitable psychotherapeutic care options for mother and child.

The recognition and management of PPD in pregnant women and young mothers by registered gynaecologists appears to be a promising strategy to offer adequate aids, in the sense of preemptive child protection, for families and to avoid or reduce the possible negative consequences for the child's development. Empirical studies are needed to check the efficacy of this strategy.

\section{Acknowledgements \\ $\nabla$}

We thank Dr. Levente Kriston for methodological advice.

\section{Conflict of Interest \\ $\nabla$}

None.

\section{References}

1 Paulson J, Bazemore S. Prenatal and postpartum depression in fathers and its association with maternal depression: a meta-analysis. JAMA 2010; 303: 1961-1969

2 Halbreich U, Karkun S. Cross-cultural and social diversity of prevalence of postpartum depression and depressive symptoms. J Affect Disord 2006; 91: 97-111

3 O'Hara M, Swain A. Rates and risk of postpartum depression - a metaanalysis. Int Rev Psychiatry 1996; 8: 37-54

$4 v$ Ballestrem CL, Strauss M, Kächele H. Contribution to the epidemiology of postnatal depression in Germany-implications for the utilization of treatment. Arch Womens Ment Health 2005; 8: 29-35

5 Schulte-Markwort E, Remschmidt $H$, Dilling $H$ et al. Internationale Klassifikation psychischer Störungen: ICD-10 Kapitel V (F). Klinisch-diagnostische Leitlinien. 8. Aufl. Bern: Verlag Hans Huber; 2005

6 Brockington I. Postpartum psychiatric disorders. Lancet 2004; 363 : 303-310

7 Spinelli M. Maternal infanticide associated with mental illness: prevention and the promise of saved lives. Am J Psychiatry 2004; 161: 15481557

8 Murray Y, Halligan S, Adams G et al. Socioemotional development in adolescents at risk for depression: the role of maternal depression and attachment style. Dev Psychopathol 2006; 18: 489-516

9 Pawlby S, Hay DF, Sharp D et al. Antenatal depression predicts depression in adolescent offspring: prospective longitudinal communitybased study. J Affect Disord 2009; 113: 236-243

10 Sidebotham P, Heron J. Child maltreatment in the "children of the nineties": a cohort study of risk factors. Child Abuse Negl 2006; 30: 497522

11 Dennis C, Chung-Lee L. Postpartum depression help-seeking barriers and maternal treatment preferences: a qualitative systematic review. Birth 2006; 33: 323-331

12 Le Strat Y, Dubertret C, Le Foll B. Prevalence and correlates of major depressive episode in pregnant and postpartum women in the United States. J Affect Disord 2011; 135: 128-138

13 Turmes L, Hornstein C. Stationäre Mutter-Kind-Einheiten in Deutschland: Ein Bericht zum Status Quo. Nervenarzt 2007; 78: 773-779

14 Dennis C, Creedy D. Psychosocial and psychological interventions for preventing postpartum depression. Cochrane Database Syst Rev 2004; 4: CD001134 
15 Riecher-Rössler A, Hofecker Fallahpour M. Die Depression in der Postpartalzeit: eine diagnostische und therapeutische Herausforderung. Schweiz Arch Neurol Psychiatr 2003; 154: 106-115

16 Stein $G$, Van den Akker 0 . The retrospective diagnosis of postnatal depression by questionnaire. J Psychosom Res 1992; 36: 67-75

17 Beck C. Screening methods for postpartum depression. J Obstet Gynecol Neonatal Nurs 1995; 24: 308-312

18 Beck C, Gable R. Postpartum depression screening scale: development and psychometric testing. Nurs Res 2000; 49: 272-282

19 Cox J, Chapman G, Murray D et al. Validation of the Edinburgh Postnatal Depression Scale (EPDS) in non-postnatal women. J Affect Disord 1996; 39: 185-189

20 Bergant A, Nguyen T, Heim K et al. Deutschsprachige Fassung und Validierung der „Edinburgh postnatal depression scale“. Dtsch Med Wochenschr 1998; 123: 35-40

21 Gibson J, McKenzie-McHarg K, Shakespeare J et al. A systematic review of studies validating the Edinburgh Postnatal Depression Scale in antepartum and postpartum women. Acta Psychiatr Scand 2009; 119: 350-364

22 Spitzer RL, Kroenke K, Williams JB. Validation and utility of a self-report version of PRIME-MD: the PHQ primary care study. Primary care evaluation of mental disorders. Patient health questionnaire. JAMA 1999; 282: $1737-1744$

23 DGPPN; BÄK; KBV et al. S3-Leitlinie/Nationale VersorgungsLeitlinie Unipolare Depression - Langfassung. 2. Aufl. [Konsultationsfassung]. Berlin: DGPPN; 2015

24 D'Amelio R, Rauccio V, Melluso J et al. Is it possible to predict postnatal depression? Research into the origin of blues and depression. The role of the gynaecologist. Clin Exp Obstet Gynecol 2006; 33: 151-153
25 Gesundheitsberichterstattung des Bundes. Bei den Ärztekammern registrierte Ärztinnen und Ärzte mit Gebiets- und Facharztbezeichnung. Online: https://www.gbe-bund.de/oowa921-install/servlet/oowa/ aw92/dboowasys921.xwdevkit/xwd_init?gbe.isgbetol/xs_start_neu/ \&p_aid=i\&p_aid=7590235\&nummer=656\&p_sprache=D\&p_indsp $=-\&$ p_aid=32564163; Stand: 17.09 .2015

26 Berner M, Schmidt E, Weinhäuptl C et al. Prävalenz, Diagnostik und Therapie weiblicher sexueller Funktionsstörungen in der gynäkologischen Praxis - Eine deutschlandweite Repräsentativbefragung. Geburtsh Frauenheilk 2010; 70: 281-287

27 Greß S, Stegmüller K. Gesundheitliche Versorgung in Stadt und Land Ein Zukunftskonzept. Wiesbaden: Landesbüro Hessen der FriedrichEbert-Stiftung; 2011

28 Weber I. Alte und neue Bundesländer - Mehr Patienten, weniger Ärzte und geringere Finanzmittel. Dtsch Arztebl 2005; 12: 540-541

29 Seehusen D, Baldwin L, Runkle $G$ et al. Are family physicians appropriately screening for postpartum depression? J Am Board Fam Pract 2005; 18: 104-112

30 Wiley C, Burke G, Gill P et al. Pediatricians' views of postpartum depression: a self-administered survey. Arch Womens Ment Health 2004; 7 : 231-236

31 Wittchen HU, Pittrow D. Prevalence, recognition and management of depression in primary care in Germany: the Depression 2000 study. Hum Psychopharmacol 2002; 17: S1-S11

32 Price S, Corder-Mabe J, Austin K. Perinatal depression screening and intervention: enhancing health provider involvement. J Womens Health 2012; 21: 447-455 